\title{
SOME ANALOGUES OF TOPOLOGICAL GROUPS
}

\author{
MADHU RAM \\ Department of Mathematics \\ University of Jammu \\ Jammu and Kashmir, India \\ e-mail: madhuram0502@gmail.com
}

\begin{abstract}
Let $(G, *)$ be a group and $\tau$ be a topology on $G$. Let $\tau^{\alpha}=\{A \subseteq$ $G: A \subseteq \operatorname{Int}(C l(\operatorname{Int}(A)))\}, g * \tau=\{g * A: A \in \tau\}$ for $g \in G$. In this paper, we establish two relations between $G$ and $\tau$ under which it follows that $g * \tau \subseteq \tau^{\alpha}$ and $g * \tau^{\alpha} \subseteq \tau^{\alpha}$, designate them by $\alpha$-topological groups and $\alpha$-irresolute topological groups, respectively. We indicate that under what conditions an $\alpha$-topological group is topological group. This paper also covers some general properties and characterizations of $\alpha$-topological groups and $\alpha$-irresolute topological groups. In particular, we prove that (1) the product of two $\alpha$-topological groups is $\alpha$-topological group, (2) if $H$ is a subgroup of an $\alpha$-irresolute topological group, then $\alpha \operatorname{Int}(H)$ is also subgroup, and (3) if $A$ is an $\alpha$-open subset of an $\alpha$-irresolute topological group, then $\langle A\rangle$ is also $\alpha$-open. In the mid of discourse, we also mention about their relationships with some existing spaces.
\end{abstract}

Keywords: $\alpha$-open sets, $\alpha$-closed sets, $\alpha$-topological groups, $\alpha$-irresolute topological group.

2010 Mathematics Subject Classification: 22A05, 54C08, 54H99.

\section{REFERENCES}

[1] M.S. Bosan, M.D. Khan and L.D.R. Kocinac, On s-Topological groups, Math. Morav. $18(2014) 35-44$. doi:10.5937/MatMor1402035B

[2] M.D. Khan and M.S. Bosan, A note on s-topological groups, Life Sci J. 11 (7s) (2014) $370-374$.

[3] M.D. Khan, A. Siab and L.D.R. Kocinac, Irresolute topological groups, Math. Morav. 19 (2015) 73-80. doi:10.5937/MatMor1501073K 
[4] M.D. Khan, S. Habib and M.S. Bosan, Quasi S-topological groups, Life Sci. J. 27 (2015) 53-57.

[5] A.S. Mashhour, I.A. Hasanein and S.N. El-Deeb, $\alpha$-continuous and $\alpha$-open mappings, Acta Math. Hung. 41 (1983) 213-218. doi:10.1007/BF01961309

[6] O. Njastad, On some classes of nearly open sets, Pacific J. Math. 15 (1965) 961-970. doi:10.2140/pjm.1965.15.961

[7] R. Noreen and M.D. Khan, Semi-connectedness in s-topological groups, J. Adv. Stud. Topol. 7 (2016). doi:10.20454/jast.2016.1024

[8] R. Noreen, M.S. Bosan and M.D. Khan, Semi-connectedness in irresolute topological groups, Life Sci J. 27 (2015) 4981-1985.

[9] T. Oner, M.B. Kandemir and B. Tanay, Semi-topological groups with respect to semicontinuity and irresoluteness, J. Adv. Stud. Topol. 4 (2013) 23-28. doi:10.20454/jast.2013.626

[10] T. Oner and A. Ozek, On semi topological groups with respect to irresoluteness, Int. J. Recent Sci. Res. 6 (2015) 7914-7916.

[11] T. Oner and A. Ozek, A note on quasi-irresolute topological groups, J. Linear Topol. Algeb. 5 (2016) 41-46.

[12] M. Ram, On almost topological groups, Math. Morav. 23 (2019) 97-106. doi:10.5937/MatMor1901097R

[13] M. Tkachenko, Paratopological and semitopological groups vs topological groups, in: K.P. Hart, J. van Mill, P. Simon (eds.), Recent Progress in General Topology III (Atlantis Press, 2014) 825-882.

doi:10.2991/978-94-6239-024-9_20

Received 25 March 2020

Revised 12 May 2020

Accepted 21 December 2020 